\title{
Prevalence and early-life determinants of mid-life multimorbidity: evidence from the 1970 British birth cohort
}

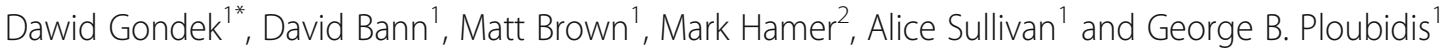

\begin{abstract}
Background: We sought to: [1] estimate the prevalence of multimorbidity at age 46-48 in the 1970 British Cohort Study - a nationally representative sample in mid-life; and [2] examine the association between early-life characteristics and mid-life multimorbidity.

Method: A prospective longitudinal birth cohort of a community-based sample from the 1970 British Cohort Study (BCS70). Participants included all surviving children born in mainland Britain in a single week in April 1970; the analytical sample included those with valid data at age 46-48 $(n=7951 ; 2016-2018)$. The main outcome was multimorbidity, which was operationalised as a binary indicator of two or more long-term health conditions where at least one of these conditions was of physical health. It also included symptom complexes (e.g., chronic pain), sensory impairments, and alcohol problems.

Results: Prevalence of mid-life multimorbidity was $33.8 \%$ at age $46-48$. Those with fathers from unskilled social occupational class (vs professional) at birth had $43 \%$ higher risk of mid-life multimorbidity (risk ratio $=1.43,95 \%$ confidence interval 1.15 to 1.77). After accounting for potential child and family confounding, an additional kilogram of birthweight was associated with $10 \%$ reduced risk of multimorbidity (risk ratio $=0.90,95 \%$ confidence interval 0.84 to 0.96); a decrease of one body mass index point at age 10 was associated with $3 \%$ lower risk (risk ratio $=1.03,95 \%$ confidence interval 1.01 to 1.05 ); one standard deviation higher cognitive ability score at age 10 corresponded to $4 \%$ lower risk (risk ratio $=0.96,95 \%$ confidence interval 0.91 to 1.00 ); an increase of one internalising problem at age 16 was equated with $4 \%$ higher risk (risk ratio $=1.04,95 \%$ confidence interval 1.00 to 1.08) and of one externalising problem at age 16 with $6 \%$ higher risk (risk ratio $=1.06,1.03$ to 1.09 ).
\end{abstract}

Conclusion: Prevalence of multimorbidity was high in mid-life (33.8\% at age 46-48) in Britain. Potentially modifiable early-life exposures, including early-life social circumstances, cognitive, physical and emotional development, were associated with elevated risk of mid-life multimorbidity.

Keywords: Determinants of health, Risk factors, Mid-life, UK, Birth cohorts

\footnotetext{
* Correspondence: dawid.gondek.14@ucl.ac.uk

${ }^{1}$ Centre for Longitudinal Studies (UCL Institute of Education), 55-59 Gordon Square, London WC1H ONU, UK

Full list of author information is available at the end of the article
}

(C) The Author(s). 2021 Open Access This article is licensed under a Creative Commons Attribution 4.0 International License, which permits use, sharing, adaptation, distribution and reproduction in any medium or format, as long as you give appropriate credit to the original author(s) and the source, provide a link to the Creative Commons licence, and indicate if changes were made. The images or other third party material in this article are included in the article's Creative Commons licence, unless indicated otherwise in a credit line to the material. If material is not included in the article's Creative Commons licence and your intended use is not permitted by statutory regulation or exceeds the permitted use, you will need to obtain permission directly from the copyright holder. To view a copy of this licence, visit http://creativecommons.org/licenses/by/4.0/ The Creative Commons Public Domain Dedication waiver (http://creativecommons.org/publicdomain/zero/1.0/) applies to the data made available in this article, unless otherwise stated in a credit line to the data. 


\section{What is already known on this topic?}

- Due to differences in the outcome definition, estimates of multimorbidity prevalence in mid-life (age 40-60) have varied extensively in high-income countries-from 15 to 80\% between 1961 and 2013.

- There is a lack of contemporary national data in Great Britain describing the burden and nature of multimorbidity.

- The association between early-life risk factors and individual health conditions have been widely studied, however, it is unknown if they are associated with multimorbidity.

\section{What this study adds}

- Prevalence of multimorbidity in mid-life (age 46-48) was $33.8 \%$ in a nationally representative birth cohort in 2016-2018.

- Disadvantaged early-life parental social class, lower birthweight, lower cognitive ability, higher childhood body-mass index, and a higher number of internalising and externalising problems were found to be associated with a higher mid-life multimorbidity.

\section{Introduction}

The prevalence of multimorbidity has increased over the last two decades in high-income countries and this trend is projected to continue [1-3]. This presents a challenge to population health, as multimorbidity is linked to polypharmacy and complex health needs [3]. Yet, research on multimorbidity is still sparse-particularly among middle-aged individuals, who will constitute the older population [4]. Due to the use of various definitions, the estimates of the prevalence of multimorbidity among middle-aged individuals (age 40-60) has ranged widely in high-income countries: from around 15 to $80 \%$ in 1961-2013 [5]. Hence, it was recommended that the research prioritises estimating multimorbidity burden using a consistent definition and identifying modifiable determinants of common clusters of diseases [4].

Early-life is arguably the most appropriate life phase for preventative efforts [6,7], hence we focused on early-life determinants of multimorbidity in this study. We identified exposures that are potentially modifiable, commonly measured, span multiple domains of early-life development and have been linked to adult morbidity. These were birthweight, socioeconomic circumstances, cognitive ability, and body-mass index (BMI), internalising and externalising problems. These exposures can increase the risk of multimorbidity through several mechanisms. For instance, per sensitive or critical period theories of life course $[8,9]$, their link might be more direct via altering neuroendocrine hormone levels, toxic stress, and increased allostatic load, which leads to damage in metabolic, cardiovascular, immune, and nervous systems $[10,11]$. Alternatively, as proposed by the chain of risks life course models [12, 13], early cognitive and social disruptions may increase the risk of harmful behaviours such as smoking or alcohol consumption adopted as coping mechanisms and leading to further damage.

Lower birthweight [13] and disadvantaged social class at birth [14] have been linked to increased multimorbidity risk, yet existing evidence is limited to regional cohorts (the Hertfordshire Cohort Study in England and the Aberdeen Children of the 1950s in Scotland respectively). The association between higher BMI and adult multimorbidity risk has, to our knowledge, only been investigated cross-sectionally $[15,16]$, despite extensive literature on its links with other health outcomes [17]. Other limitations of previous studies, which this research aims to address, include using a study-specific definitions of multimorbidity [13-16, 18], not accounting for a wide range of sources of confounding-particularly family characteristics $[14-16,18]$, and focusing on individual risk factors [14-16] as opposed to ones ranging across various domains of development. We have not identified any studies of the association between childhood cognitive ability and multimorbidity, despite its link with long-term sickness in mid-life, which was found to be independent of adult social class [19]. Childhood emotional development, defined as internalising and externalising problems, has also not been studied in the context of multimorbidity. However, longitudinal studies conducted in the United Kingdom have found an association between negative affect, aggression as well as anxiety at age 13-15 with somatic and psychiatric symptoms at age 43 [18].

The 1970 British Cohort Study (BCS70) is a prospective representative cohort of those born around 1970 in Great Britain, and it comprises a rich array of information collected from birth until mid-life (age 46-48) including recently collected (in 2016-2018) biomedical as well as self-reported data [20]. Hence, this dataset is well suited to address the objectives of our study. These are: (1) to estimate the prevalence of multimorbidity in midlife (age 46-48) in Great Britain; and (2) to examine the association between early-life characteristics and mid-life multimorbidity.

\section{Methods \\ Participants}

The history, design, and features of the BCS70 have been described elsewhere [21, 22]. In brief, the cohort includes all surviving children born in England, Scotland and Wales in a single week in April $1970(n=17196)$ [21]. Our analytical sample included those who 
participated in the data sweep at age 46-48 (from 2016 to $2018 ; n=7951$ ). This survey aimed to collect key information on cohort members' socio-economic circumstances and health, with a range of bio-measures administered by a nurse (e.g., anthropometric and blood pressure measurements) [20].

\section{Measures}

\section{Multimorbidity}

Multimorbidity was operationalised according to the definition recommended by the National Institute for Health and Care Excellence (NICE): presence of "two or more long-term health conditions where at least one of these conditions must be a physical health condition" [p.17, 23]. These can include physical and mental health conditions, symptom complexes (e.g., chronic pain), sensory impairment, alcohol and substance misuse [23]. Multimorbidity comprised self-reported conditions diagnosed since the previous interview (4 years or more) (e.g., asthma, heart problems; see supplemental table 1 for the full list), alcohol problems (Alcohol use disorders identification test; primary care $\geq 5$ ) [24], mental health problems (Malaise Inventory $\geq 4$ ) [25], hypertension (systolic blood pressure $\geq 140 \mathrm{mmHg}$ or diastolic blood pressure $\geq 90 \mathrm{mmHg}$ or taking medications), and diabetes (Glycated Haemoglobin of $\geq 48 \mathrm{mmol} / \mathrm{mol}(\geq 6.5 \%)$ or taking medications; see supplemental table 2).

\section{Exposures}

Birthweight $(\mathrm{kg})$ was recorded in the birth survey by a midwife who attended the delivery. BMI at age 10 was derived from a measure of weight and height obtained by a range of different health practitioners. Father's social class at birth (SES) refers to the occupation of the father coded according to the Registrar General's classification (I - professional, II - managerial and technical, III - skilled non-manual/manual, IV - partly-skilled, and V - unskilled) [26]. Social class at birth was selected, as it broadly encompasses socioeconomic circumstances and is strongly related to other dimensions of socioeconomic circumstances such as education or income [27].

Cognitive ability was assessed by a modified version of the British Ability Scales at age 10 [28]. Following the approach used in previous studies, we performed a principal component analysis for each of the verbal and nonverbal subtests, to obtain scores indicating a general cognitive ability factor (g) $[29,30]$. The scores were standardised to a mean of zero and a standard deviation of one. Internalising and externalising problems were captured with the modified version of the Rutter A scale at age 16, completed by mothers of the participants as part of the home interview [31]. See supplemental table 3 for details on measures of exposures.

\section{Potential confounding}

We controlled for a range of child and family characteristics (see supplemental table 4 for details on measures of confounding), which were likely to be associated with the exposure and outcome (supplemental table 5 for the list of relevant studies) and were not on the causal pathway between these variables [32]. These include gestational age, birthweight and father's social class at birthwhen they were not used as exposures, maternal smoking during pregnancy, breastfeeding, mother's height, mother's marital status at birth, mother being a teen at birth, household tenure (age 5-10), overcrowding (>1 person per room at age 5), teacher's report of parental interest in child's education (age 10), length of time absent from school due to illness (age 10) and parental divorce (age 0-16).

\section{Missing data}

Multimorbidity was deemed missing if participants had incomplete information on at least one component of multimorbidity ( $n=3793$ out of 7951 defined as the study sample). To restore sample representativeness and reduce selection bias, we used multiple imputation with chained equations generating 50 datasets [33]. To investigate sensitivity of the estimates due to missing information, the prevalence of multimorbidity is also presented under different missing data generating mechanisms and across imputations based on samples with varying missing data inclusion criteria as well as the associations are reported using complete cases (see supplemental text 1 and supplemental tables 6 for more details on missing data strategy).

\section{Analysis}

Exposures-multimorbidity association

Associations between exposures and multimorbidity (age 46-48) were estimated using a log binomial model with robust standard errors, expressed as risk ratios. Since the outcome was common $(<20 \%)$, using this model helps to avoid bias due to noncollapsibility of the odds ratios [34]. We present gender-adjusted estimates, as we found no differential associations between men and women, and further adjusted models that account for potential child and family confounding (i.e., common causes of both exposures and multimorbidity).

\section{Exploratory analysis - multimorbidity as clusters of conditions}

Due to heterogeneous definitions of multimorbidity [4, 35], we additionally investigated the determinants of five most common pairs of conditions (and their components): mental health morbidity and hypertension, mental health morbidity and arthritis, mental health morbidity and diabetes, mental health morbidity 
and asthma/bronchitis, diabetes and hypertension [36]. As the clusters used in these analyses were derived from the multimorbidity outcome, they are likely to be closely related hence increasing family-wise error rate. Thus, we employed a more stringent $p$-value threshold of $0.003-$ using the Bonferroni correction ( $\alpha=0.05$ divided by 20 tests) [37]. We evaluated our findings using this threshold, but also considered the strength of associations, coverage of confidence intervals and pattern of $p$-values.

\section{Ethical considerations}

This work is a secondary analysis. All methods were carried out following relevant guidelines and regulations. The Age 46 Survey, including the collection of blood, was approved by the Health Research Authority's London - Central Research Ethics Committee. All participants provided written informed consent after a thorough explanation of the research procedures.

\section{Results}

Prevalence of multimorbidity

The prevalence of multimorbidity in BCS70 at age 4648 was $33.8 \%$. The estimates of multimorbidity prevalence based on different definitions of the sample were relatively consistent (see supplemental table 7). The most prevalent individual health outcomes were highrisk drinking (26.3\%), recurrent back problems (20.9\%), and mental health problems (19.1\%) (see Table 1). Among the most prevalent chronic physical health conditions were asthma/bronchitis (11.6\%) and arthritis (7.7\%).

\section{Exposures-mid-life multimorbidity association}

In gender-adjusted models, all exposures were associated with a greater risk of multimorbidity at age 46-48: lower birthweight, lower cognitive ability at age 10, higher BMI at age 10, more internalising and externalising problems at age 16 as well as a more disadvantaged father's social classes at birth $(p<0.001)$ : with unskilled class having $43 \%$ higher risk of multimorbidity (risk ratio; $R R=1.43,95 \%$ confidence interval 1.15 to 1.77 ) (Table 2).

Adjustment for potential confounding had little effect on the strength of the associations. An additional kilogram of birthweight was associated with $10 \%$ reduced risk of multimorbidity ( $R R=0.90,0.84$ to 0.96 ); a decrease of one point on BMI scale was associated with $3 \%$ lower risk $(\mathrm{RR}=1.03,1.01$ to 1.05$)$; one standard deviation higher score on cognitive ability measure corresponded to $4 \%$ lower risk ( $R R=0.96,95 \%$ CI 0.91 to 1.00); increase of one internalising problem was equated with $4 \%$ higher risk ( $R R=1.04,1.00$ to 1.08$)$ and of one externalising problem with $6 \%$ higher risk $(R R=1.06$, 1.03 to 1.09 ).
Table 1 Descriptive statistics of the health outcomes and earlylife exposures

\begin{tabular}{|c|c|}
\hline \multirow[t]{2}{*}{ Outcomes (age) } & $N=7951$ \\
\hline & $\%$ \\
\hline Multimorbidity $(46-48)^{*}$ & $33.8(32.6,35.0)$ \\
\hline Chronic fatigue syndrome (46-48) & $1.5(1.2,1.7)$ \\
\hline Arthritis (46-48) & $7.7(7.1,8.3)$ \\
\hline Stroke (46-48) & $0.5(0.4,0.7)$ \\
\hline Heart problems (46-48) & $3.0(2.6,3.4)$ \\
\hline Eyes problems (46-48) & $4.9(4.5,5.4)$ \\
\hline Hearing problems (46-48) & $5.8(5.2,6.3)$ \\
\hline Recurrent back problems (46-48) & $20.9(20.0,21.8)$ \\
\hline Drinking problems (46-48) & $26.3(25.3,27.4)$ \\
\hline Hypertension (46-48) & $15.7(14.8,16.6)$ \\
\hline Diabetes (46-48) & $4.7(4.1,5.2)$ \\
\hline Mental health morbidity (46-48) & $19.1(18.3,20.0)$ \\
\hline Asthma/bronchitis (46-48) & $11.6(10.9,12.3)$ \\
\hline Convulsion, fit, epileptic seizure (46-48) & $1.1(0.8,1.3)$ \\
\hline \multirow[t]{2}{*}{ Cancer or leukaemia (46-48) } & $1.6(1.4,1.8)$ \\
\hline & Mean (standard error) \\
\hline Mean number of conditions (46-48) & $1.24(0.02)$ \\
\hline Systolic blood pressure, mmHg (46-48) & $125.39(0.19)$ \\
\hline Diastolic blood pressure, mmHg (46-48) & $77.73(0.13)$ \\
\hline $\mathrm{HbA1C}, \%(46-48)$ & $5.59(0.01)$ \\
\hline Malaise Inventory (46-48) & $1.76(2.12)$ \\
\hline AUDIT-PC (46-48) & $3.88(2.58)$ \\
\hline Exposures (age) & Mean (standard error) \\
\hline Birthweight (0) & $3.31(0.01)$ \\
\hline Cognitive ability (10) & $0.16(0.01)$ \\
\hline Body mass index (10) & $16.9(0.03)$ \\
\hline Internalising problems (16) & $0.93(0.02)$ \\
\hline \multirow[t]{2}{*}{ Externalising problems (16) } & $0.68(0.02)$ \\
\hline & $\%$ \\
\hline \multicolumn{2}{|l|}{ Father's social class at birth (0) } \\
\hline I - professional & 6.1 \\
\hline II - managerial and technical & 13.8 \\
\hline III - skilled non-manual/manual & 60.8 \\
\hline IV - partly-skilled & 13.9 \\
\hline V - unskilled & 5.5 \\
\hline
\end{tabular}

*Note. The outcome data were collected over the 2 years when participants were $46-48$ year old

$A U D I T-P C=$ alcohol use disorders identification test- primary care

\section{Exploratory analysis-multimorbidity as clusters of conditions}

The prevalence of pairs of conditions, in multiply imputed data, were: mental health $(\mathrm{MH}) /$ hypertension 
Table 2 Association between early-life exposures and multimorbidity at age 46-48

\begin{tabular}{|c|c|c|}
\hline \multirow[t]{2}{*}{$N=7951$} & \multicolumn{2}{|c|}{ Relative risk $(95 \% \mathrm{Cl})$} \\
\hline & Gender-adjusted & Confounding-adjusted \\
\hline Father's social class at birth (age 0 ) & & $N / A^{a}$ \\
\hline I - professional & 1.00 & 1.00 \\
\hline II - managerial and technical & $1.14(0.94,1.40)$ & - \\
\hline III - skilled non-manual/manual & $1.30(1.09,1.55)$ & - \\
\hline IV - partly-skilled & $1.43(1.18,1.74)$ & - \\
\hline$V$ - unskilled & $1.43(1.15,1.77)$ & - \\
\hline Birthweight (age 0) & $0.86(0.80,0.91)$ & $0.90(0.84,0.96)^{b}$ \\
\hline Cognitive ability (age 10) & $0.91(0.87,0.95)$ & $0.96(0.91,1.00)^{c}$ \\
\hline BMI (age 10) & $1.03(1.01,1.05)$ & $1.03(1.01,1.05)^{\mathrm{d}}$ \\
\hline Internalising problems (age 16) & $1.07(1.04,1.11)$ & $1.04(1.00,1.08)^{\mathrm{e}}$ \\
\hline Externalising problems (age 16) & $1.09(1.07,1.12)$ & $1.06(1.03,1.09)^{f}$ \\
\hline
\end{tabular}

${ }^{a}$ Not adjusted for any other variables as they may potentially lie on the causal pathway

${ }^{\mathrm{b}}$ Adjusted for gender, father's social class at birth, mother ever smoked during pregnancy, mother's height, mother's marital status at birth, and mother being a teen at birth

'Adjusted for gender, father's social class at birth, birthweight, mother ever smoked during pregnancy, mother breastfed, mother's height, mother's marital status at birth, mother being a teen at birth, household tenure (age 5-10), parental interest in child's education (age 10), overcrowding (age 5), length of time absent from school due to illness (age 10), parental divorce (age 0-16), mother's mental health (age 10), and BMI (age 10)

${ }^{\mathrm{d}}$ Adjusted for gender, father's social class at birth, birthweight, mother ever smoked during pregnancy, mother breastfed, mother's height, mother's marital status at birth, mother being a teen at birth, household tenure (age 5-10), parental interest in child's education (age 10), overcrowding (age 5), length of time absent from school due to illness (age 10), parental divorce (age 0-16), mother's mental health (age 10), and cognitive ability (age 10)

${ }^{\mathrm{e}}$ Adjusted for gender, father's social class at birth, birthweight, mother ever smoked during pregnancy, mother breastfed, mother's height, mother's marital status at birth, mother being a teen at birth, household tenure (age 5-10), parental interest in child's education (age 10), overcrowding (age 5), length of time absent from school due to illness (age 10), parental divorce (age 0-16), mother's mental health (age 10), cognitive ability (age 10), BMI (age 10), and externalising problems (age 16)

${ }^{f}$ Adjusted for gender, father's social class at birth, birthweight, mother ever smoked during pregnancy, mother breastfed, mother's height, mother's marital status at birth, mother being a teen at birth, household tenure (5-10), parental interest in child's education (age 10), overcrowding (age 5), length of time absent from school due to illness (age 10), parental divorce (age 0-16), mother's mental health (age 10) cognitive ability (age 10), BMI (age 10), and internalising problems (age 16)

(4.1\%), MH/asthma (3.3\%), $\mathrm{MH} /$ arthritis $(2.5 \%)$, diabetes/hypertension (2.1\%), $\mathrm{MH} /$ diabetes (1.4\%).

As presented in Table 3 there was strong evidence (at the Bonferroni corrected $p<0.003$ ) for the association between father's SES at birth and clusters including mental health problems: $\mathrm{MH} /$ hypertension (for unskilled vs professional class: $\mathrm{RR}=2.92,1.23$ to 6.94 ) and $\mathrm{MH} /$ arthritis $(\mathrm{RR}=3.41,1.46$ to 7.95$)$. These associations were somewhat stronger than the ones found for the individual conditions, as shown in Table 4 arthritis (for unskilled vs professional class: $R R=1.86,1.19$ to 2.91 ), hypertension ( $R R=1.52,1.05$ to 2.20 ), and mental health problems $(\mathrm{RR}=1.54,1.14$ to 2.10 ; with $p$-value being slightly above the Bonferroni threshold: $p=0.005)$. However, the association between father's SES and diabetes was also particularly strong (e.g., for unskilled vs professional class: $\mathrm{RR}=3.29,1.26$ to 8.56 ).

Birthweight was associated with diabetes and hypertension, with $1 \mathrm{~kg}$ higher weight being linked with $29 \%$ $(\mathrm{RR}=0.71,0.55$ to 0.91$)$ and $20 \%(\mathrm{RR}=0.80,0.72$ to 0.89 ) lower risk of having these conditions respectively (Table 4). Cognitive ability was associated with $\mathrm{MH} /$ arthritis $(\mathrm{RR}=0.75,0.63$ to 0.89 ), and mental health problems ( $R R=0.90,0.84$ to 0.96 ) (Tables 3 and 4). Externalising problems were not found to be linked with any cluster or individual condition. Internalising problems were linked with clusters including mental health problems: $\mathrm{MH}$ /hypertension, $\mathrm{MH}$ /arthritis, $\mathrm{MH}$ /asthma and with mental health morbidity as an individual condition (Table 4). BMI at age 10 had the strongest association with diabetes/hypertension clusters $(R R=1.25$, 1.16 to 1.34 ) and it was linked with diabetes and hypertension as individual conditions and their clusters with mental health (Tables 3 and 4).

\section{Supplementary analyses}

First, we tested-using the Wald test-for non-linear associations between BMI, birthweight and multimorbidity by including squared and linear terms of these exposures in unadjusted regression models, but there was no evidence of departure from linearity.

Second, as a sensitivity check, we estimated the Evalue, which indicates the minimum strength of association that an unmeasured confounding would need to have with both the treatment and outcome to fully explain away a specific treatment-outcome association, after conditioning on the measured covariates [38]. As shown by supplemental table 8 , the association between each early-life exposure and multimorbidity at age 4648 , could be explained away by an unmeasured 
Table 3 The association between early-life risk factors and multimorbidity clusters at age 46-48

\begin{tabular}{|c|c|c|c|c|c|}
\hline \multirow[t]{2}{*}{$N=7951$} & $\mathrm{MH}+$ hypertension & $\mathrm{MH}+$ arthritis & $\mathrm{MH}+$ diabetes & $\mathrm{MH}+$ asthma & Diabetes + hypertension \\
\hline & \multicolumn{5}{|l|}{ Relative risk $(95 \% \mathrm{Cl})$} \\
\hline \multicolumn{6}{|l|}{ Father's social class at birth ${ }^{a}$} \\
\hline I - professional (reference) & $1.00^{*}$ & $1.00^{*}$ & 1.00 & 1.00 & 1.00 \\
\hline II - managerial and technical & $1.27(0.53,3.04)$ & $1.19(0.51,2.80)$ & $2.69(0.35,20.83)$ & $1.67(0.78,3.56)$ & $2.04(0.52,7.99)$ \\
\hline III - skilled non-manual/manual & $2.32(1.11,4.87)$ & $1.53(0.72,3.26)$ & $4.40(0.67,29.13)$ & $1.68(0.83,3.40)$ & $3.01(0.85,10.61)$ \\
\hline IV - partly-skilled & $2.96(1.36,6.44)$ & $1.92(0.85,4.35)$ & $5.13(0.56,30.32)$ & $2.03(0.97,4.26)$ & $3.59(0.97,13.35)$ \\
\hline$V$ - unskilled & $2.92(1.23,6.94)$ & $3.41(1.46,7.95)$ & $5.92(0.78,44.64)$ & $2.04(0.85,4.89)$ & $3.60(0.92,14.09)$ \\
\hline Birthweight ${ }^{b}$ & $0.83(0.65,1.05)$ & $0.85(0.64,1.12)$ & $1.03(0.66,1.61)$ & $0.83(0.65,1.07)$ & $0.72(0.49,1.06)$ \\
\hline Cognitive ability (age 10) ${ }^{c}$ & $0.85(0.72,1.00)$ & $0.75(0.63,0.89)^{*}$ & $0.80(0.61,1.06)$ & $0.85(0.72,1.00)$ & $0.91(0.73,1.12)$ \\
\hline BMI (age 10) ${ }^{d}$ & $1.11(1.05,1.18)^{*}$ & $1.03(0.96,1.12)$ & $1.16(1.06,1.28)^{*}$ & $1.04(0.98,1.11)$ & $1.25(1.16,1.34)^{*}$ \\
\hline Internalising problems (age 16) & $1.21(1.09,1.34)^{*}$ & $1.17(1.03,1.33)^{*}$ & $1.09(0.87,1.38)$ & $1.25(1.12,1.39)^{*}$ & $0.97(0.79,1.19)$ \\
\hline Externalising problems (age 16) ${ }^{f}$ & $1.00(0.90,1.11)$ & $1.06(0.95,1.19)$ & $1.04(0.87,1.24)$ & $1.02(0.91,1.14)$ & $1.04(0.89,1.22)$ \\
\hline
\end{tabular}

${ }^{\mathrm{a} A d j u s t e d ~ f o r ~ g e n d e r ~}$

${ }^{\mathrm{b}}$ Adjusted for gender, father's social class at birth, mother ever smoked during pregnancy, mother's height, mother's marital status at birth, and mother being a teen at birth

'Adjusted for gender, father's social class at birth, birthweight, mother ever smoked during pregnancy, mother breastfed, mother's height, mother's marital status at birth, mother being a teen at birth, household tenure (age 5-10), parental interest in child's education (age 10), overcrowding (age 5), length of time absent from school due to illness (age 10), parental divorce (age $0-16$ ), mother's mental health (age 10), and BMI (age 10)

${ }^{\mathrm{d}}$ Adjusted for gender, father's social class at birth, birthweight, mother ever smoked during pregnancy, mother breastfed, mother's height, mother's marital status at birth, mother being a teen at birth, household tenure (age 5-10), parental interest in child's education (age 10), overcrowding (age 5), length of time absent from school due to illness (age 10), parental divorce (age 0-16), mother's mental health (age 10), and cognitive ability (age 10)

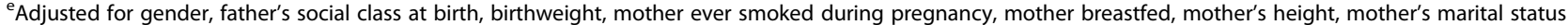
at birth, mother being a teen at birth, household tenure (age 5-10), parental interest in child's education (age 10), overcrowding (age 5), length of time absent from school due to illness (age 10), parental divorce (age 0-16), mother's mental health (age 10), cognitive ability (age 10), BMI (age 10), and externalising problems (age 16)

${ }^{f}$ Adjusted for gender, father's social class at birth, birthweight, mother ever smoked during pregnancy, mother breastfed, mother's height, mother's marital status at birth, mother being a teen at birth, household tenure (age 5-10), parental interest in child's education (age 10), overcrowding (age 5), length of time absent from school due to illness (age 10), parental divorce (age 0-16), mother's mental health (age 10) cognitive ability (age 10), BMI (age 10), and internalising problems (age 16)

*Significant at $p$-value (after the Bonferroni correction) $=0.003$ (for father's SES at birth, it refers to all categories combined)

confounding that was associated with both the exposure and outcome by a risk ratio of at least 1.21 , above and beyond the measured confounding. This value is stronger than the association between any measured exposure or confounder and the outcome in this study, but the potential for bias due to unobserved confounding cannot be fully ruled out.

Third, we tested the association between the exposures and multimorbidity after excluding mental health problems from the definition of multimorbidity. We found no association between internalising problems and alternatively-defined multimorbidity in the fully-adjusted model ( $R R=1.00,0.98$ to 1.02 ; see supplemental table 9 for all estimates).

Finally, we ran final models for each exposure with complete cases only (see supplemental table 9 for all estimates). The gender-adjusted estimates were highly comparable to the ones obtained with the imputed sample. However, estimates from confounding-adjusted models were highly imprecise with wide confidence intervals, particularly for birthweight $(\mathrm{RR}=0.95,0.86$ to $1.05 ; n=3835)$, cognitive ability $(\mathrm{RR}=1.01,0.92$ to 1.10 ; $n=1763)$, internalising problems $(\mathrm{RR}=1.01,0.93$ to
$1.10 ; n=1232)$, and externalising problems $(R R=1.04$, 0.97 to $1.11 ; \mathrm{n}=1232$ ).

\section{Discussion}

\section{Main findings}

The prevalence of multimorbidity in Britain was 33.8\% at age 46-48-based on the nationally representative data for midlife population. Being in a less advantaged social classes at birth, lower birthweight, lower cognitive ability, higher BMI-both at age 10, more externalising and internalising problems at age 16 were found to be associated with higher mid-life multimorbidity after multiple potential sources of confounding were accounted for.

These associations reflected different patterns of association with the components of multimorbidity. Higher childhood BMI and lower birthweight were linked with increased risk of diabetes and hypertension; internalising problems and cognitive ability were most strongly associated with comorbidities including adult mental health problems; a more disadvantaged father's SES was linked with diabetes and $\mathrm{MH} /$ hypertension as well as $\mathrm{MH} /$ arthritis clusters. Externalising problems had a very weak 
Table 4 The association between early-life risk factors and individual conditions at age 46-48

\begin{tabular}{|c|c|c|c|c|c|}
\hline \multirow[t]{2}{*}{$N=7951$} & Mental health & Arthritis & Diabetes & Asthma & Hypertension \\
\hline & \multicolumn{5}{|c|}{ Relative risk $(95 \% \mathrm{Cl})$} \\
\hline \multicolumn{6}{|l|}{ Father's social class at birth ${ }^{\mathrm{a}}$} \\
\hline I - professional (reference) & 1.00 & $1.00^{*}$ & 1.00 & 1.00 & $1.00^{*}$ \\
\hline II - managerial and technical & $1.15(0.89,1.50)$ & $0.86(0.56,1.36)$ & $2.11(0.83,5.36)$ & $1.31(0.96,1.80)$ & $1.05(0.75,1.48)$ \\
\hline III - skilled non-manual/manual & $1.28(1.01,1.61)$ & $1.29(0.89,1.86)$ & $2.94(1.22,7.10)$ & $1.16(0.87,1.54)$ & $1.41(1.05,1.88)$ \\
\hline IV - partly-skilled & $1.47(1.14,1.89)$ & $1.25(0.83,1.89)$ & $3.38(1.37,8.35)$ & $1.15(0.83,1.58)$ & $1.66(1.22,2.27)$ \\
\hline V- unskilled & $1.54(1.14,2.10)$ & $1.86(1.19,2.91)$ & $3.29(1.26,8.56)$ & $1.09(0.73,1.63)$ & $1.52(1.05,2.20)$ \\
\hline Birthweight $^{\mathrm{b}}$ & $0.96(0.87,1.06)$ & $0.95(0.81,1.10)$ & $0.71(0.55,0.91)$ & $0.85(0.75,0.96)$ & $0.80(0.72,0.89)^{*}$ \\
\hline Cognitive ability (age 10$)^{c}$ & $0.90(0.84,0.96)^{*}$ & $0.92(0.84,1.02)$ & $0.93(0.79,1.08)$ & $0.98(0.90,1.06)$ & $0.93(0.87,1.00)$ \\
\hline BMI (age 10) ${ }^{d}$ & $1.02(1.00,1.05)$ & $1.03(0.99,1.07)$ & $1.19(1.13,1.25)^{*}$ & $1.00(0.97,1.04)$ & $1.10(1.06,1.13)^{*}$ \\
\hline Internalising problems (age 16) & $1.18(1.13,1.24)^{*}$ & $1.06(0.97,1.15)$ & $0.97(0.85,1.12)$ & $1.05(0.98,1.12)$ & $1.02(0.95,1.09)$ \\
\hline Externalising problems (age 16) ${ }^{f}$ & $1.01(0.97,1.06)$ & $1.08(1.00,1.15)$ & $1.07(0.95,1.20)$ & $1.03(0.96,1.10)$ & $1.02(0.96,1.08)$ \\
\hline
\end{tabular}

${ }^{\mathrm{a} A d j u s t e d}$ for gender

${ }^{\mathrm{b}}$ Adjusted for gender, father's social class at birth, mother ever smoked during pregnancy, mother's height, mother's marital status at birth, and mother being a teen at birth

'Adjusted for gender, father's social class at birth, birthweight, mother ever smoked during pregnancy, mother breastfed, mother's height, mother's marital status at birth, mother being a teen at birth, household tenure (age 5-10), parental interest in child's education (age 10), overcrowding (age 5), length of time absent from school due to illness (age 10), parental divorce (age 0-16), mother's mental health (age 10), and BMI (age 10)

${ }^{\mathrm{d}}$ Adjusted for gender, father's social class at birth, birthweight, mother ever smoked during pregnancy, mother breastfed, mother's height, mother's marital status at birth, mother being a teen at birth, household tenure (age 5-10), parental interest in child's education (age 10), overcrowding (age 5), length of time absent from school due to illness (age 10), parental divorce (age 0-16), mother's mental health (age 10), and cognitive ability (age 10)

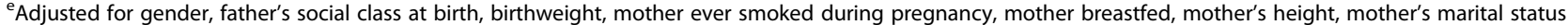
at birth, mother being a teen at birth, household tenure (age 5-10), parental interest in child's education (age 10), overcrowding (age 5), length of time absent from school due to illness (age 10), parental divorce (age 0-16), mother's mental health (age 10), cognitive ability (age 10), BMI (age 10), and externalising problems (age 16)

${ }^{f}$ Adjusted for gender, father's social class at birth, birthweight, mother ever smoked during pregnancy, mother breastfed, mother's height, mother's marital status at birth, mother being a teen at birth, household tenure (age 5-10), parental interest in child's education (age 10), overcrowding (age 5), length of time absent from school due to illness (age 10), parental divorce (age 0-16), mother's mental health (age 10) cognitive ability (age 10), BMI (age 10), and internalising problems (age 16)

*Significant at $p$-value (after the Bonferroni correction) $=0.003$ (for father's social class at birth, it refers to all categories combined)

association with the individual conditions or their clusters, despite being linked with the overall multimorbidity outcome.

\section{Comparison with previous studies and interpretation}

The prevalence of multimorbidity in our study was comparable with the most comprehensive estimate of multimorbidity in mid-life in the UK-which was $30.4 \%$ among over 1.7 million general practice patients aged 45-64 in 2007 [39].

Early-life BMI was found to be associated with multimorbidity, which is consistent with the previous literature on a range of adult morbidity outcomes as well as multimorbidity specifically $[15-17,40]$. The association between childhood BMI and diabetes and hypertension, found in our study, was also seen in both traditional observational research [17] and Mendelian randomisation studies, in which genes are employed as instrumental variables [41]. The link between BMI and diabetes and hypertension may be due to an increased risk of dyslipidaemia and systemic inflammation, which may constitute a common pathway to the development of both conditions $[42,43]$.
Externalising and internalising problems were previously found to be associated with a range of measures of adult morbidity [44-46]; and with co-existing somatic and psychiatric symptoms in mid-life [18]. In our study, externalising problems appeared to increase the risk of overall multimorbidity to a much larger extent than its major individual components. Several potential mechanisms are likely to link early-life mental health problems with adult multimorbidity. According to the allostatic stress model, exposure to chronic stressors may result in physiological dysregulation, which predisposes an individual to poor health [47]. For instance, there is evidence for the association between children's depression and worse immune functioning [48]. In addition, internalising and, particularly, externalising problems may have a more indirect effect on later multimorbidity, through their link with negative health behaviours, such as smoking, physical activity, and drinking [49-53].

The link between early-life cognitive ability and adult morbidity has been previously indicated [19, 46], yet there is no existing evidence on multimorbidity. We found evidence for a modest association, where an increase of one standard deviation in cognitive ability (around 15 points on a standard general intelligence 
test) was associated with $4 \%$ decrease in the probability of multimorbidity. Potential pathways between early-life cognitive ability and adult multimorbidity, include better self-care, indirect link via health behaviours or shared pathways with education or socioeconomic position [54].

Father's social class at birth was associated with multimorbidity in our study, which is consistent with the extensive literature on adult morbidity $[14,29,55-58]$ and multimorbidity specifically $[5,14]$. Our research adds to this literature by showing a particularly strong association between father's SES and mental health problems clustered with hypertension or arthritis. Previous research showed that the relationship between early-life socioeconomic circumstances and adult morbidity is partially mediated by cognitive ability, educational attainment, and school type [14]. Life course theory and related findings also suggest that early-life socioeconomic position increases the risk of other adverse exposures, such as negative health behaviours or unfavourable adult socioeconomic circumstances, which have a cumulative effect on health over the lifespan [59].

In contrast to our results, the association between birthweight and multimorbidity was not previously found [13]. However, the effect size in our study was modest, with $10 \%$ decrease in risk corresponding to $1 \mathrm{~kg}$ change in birthweight; or $1.6 \%$ avoided cases assuming causality, if $20 \%$ with the lowest weight were "shifted" to the mean of other $80 \%$. Overall, the evidence on the association between low birthweight and adult morbidity is somewhat inconsistent [60]. It appears that birthweight may be an important exposure for diabetes and hypertension, as shown by our analysis and other observational studies [61, 62]. However, findings from Mendelian Randomization studies suggest that only the link with diabetes may be causal $[61,62]$. This may be due to prenatal growth stress leading to metabolic reprogramming beginning in utero [63, 64], according to the Barker hypothesis [65].

\section{Strengths and limitations}

To the best of our knowledge, this is the first study examining the association between emotional development, cognitive ability and multimorbidity. The main strength of our study is that it used a contemporary and representative sample of the mid-life population born in Britain and-contrary to the previous researchaccounted for multiple sources of confounding, particularly parental characteristics. However, there is always a risk of bias in the estimates based on observational studies due to omitting potential confounding, for instance, genetic factors that may affect both early-life physical and emotional development and later health.

Our work relied on self-reported health outcomes. However, we also included objectively measured diabetes and hypertension, which are free from biases related to self-reporting. In addition, self-reports appeared to be reliable measures in our study, as we found a strong agreement between self-reported and objectively measured hypertension and diabetes (89 and 98\% respectively; with fair-0.51-and good-0.74-Cohen's Kappa). One potential limitation of the study was that we could not determine from available information how chronic some of the included conditions were. For instance, although stroke or hearing problems are typically considered as having long-term consequences, they might have been more acute in our study.

Another limitation of our study, common to research using prospective longitudinal data, is selective attrition and a large proportion of missing data. Hence, we used multiple imputation to reduce bias. Multiple imputation works under the missing at random (MAR) assumption, which implies that systematic differences between the missing and observed values can be explained by the observed data [66, 67]. We enriched the imputation model to maximise the plausibility of the MAR assumption with auxiliary variables (self-perceived general health, individual health conditions under multimorbidity outcome and smoking), which were not part of the substantive model of interest, but they were related to the probability of missingness and/or related to the incomplete outcome. We obtained similar estimates of multimorbidity prevalence from analyses under different missing data generating mechanisms (MCAR vs MAR) and across imputations based on samples with varying missing data inclusion criteria, which provides evidence for the robustness of the findings. However, it must be acknowledged that confounding-adjusted analyses using complete cases were highly imprecise due to missing data in the exposures, outcome and confounding factors. However, these estimates are likely to be biased, as they are based on the sample that is highly selective due to attrition [68].

\section{Conclusions and implications}

Multimorbidity affects over one-third of people born in Britain in 1970. Co-occurring mental and physical health conditions, such as diabetes or hypertension, appear to be particularly important comorbidities to target-due to their detrimental link with overall functioning [6971]. Early-life socioeconomic disadvantage, low birthweight, high BMI, low cognitive ability and poor emotional development were all associated with a higher risk of mid-life multimorbidity and various clusters of conditions. Hence, if the presented associations reflect causal effects, reducing their impact or prevalence, through both health promotion and primary prevention, may improve various aspects of mid-life health. 


\section{Supplementary Information}

The online version contains supplementary material available at https://doi. org/10.1186/s12889-021-11291-w.

Additional file 1: Table S1. Description of self-reported outcome variables under multimorbidity definition. Table S2. Description of objectively measured outcome variables under multimorbidity definition. Table S3. Description of the exposures. Table S4. Description of potential confounding. Table S5. Key characteristics of main relevant studies. Supplemental text 1. Missing data strategy. Table S6. Frequency and predictors of missing data in the exposures and the outcome. Table S7. Multimorbidity prevalence at age 46-48 based on different sample definitions. Table S8. The risk ratio and E-values for the association between each exposure and multimorbidity at age 46-48 in the fully adjusted models. Table S9. Association between early-life exposures and multimorbidity at age 46-48 in the sample with complete cases only and using a multimorbidity definition without mental health morbidity.

\section{Acknowledgements}

Dawid Gondek would like to thank Economic and Social Research Council $(E S R C)+3$ PhD for the support and participants of the BCS70 for their contribution to this great data resource. We thank the Centre for Longitudinal Studies (CLS), UCL Institute of Education, for the use of these data and the UK Data Service for making them available. Neither CLS nor the UK Data Service bear any responsibility for the analysis or interpretation of these data.

\section{Authors' contributions}

DG is a corresponding author. DG, GP, DB conceived and designed the study. GP and DB supervised the study. DG performed the statistical analysis. $\mathrm{DG}, \mathrm{DB}, \mathrm{MB}, \mathrm{MH}, \mathrm{AS}, \mathrm{GP}$ contributed to interpretation of data, revised the manuscript and approved the final version before submission. DG and GP are the guarantors and attest that all listed authors meet authorship criteria and that no others meeting the criteria have been omitted.

\section{Funding}

Dawid Gondek is supported by Economic and Social Research Council (ESRC) + 3 PhD studentship. The study is also supported by ESRC grant: ES/ M001660/1. The funder of the study had no role in the study design, data collection, data analysis, data interpretation, or the writing of the report. The corresponding author had full access to all the data in the study and had final responsibility for the decision to submit for publication.

\section{Availability of data and materials}

Cohort data comply with ESRC data sharing policies, readers can access data via the UK Data Archive (www.data-archive.ac.uk), through a formal request.

\section{Declarations}

\section{Ethics approval and consent to participate}

The Age 46 Survey, including the collection of blood, was approved by the Health. Research Authority's London - Central Research Ethics Committee. Participants provided verbal consent during the interviews. Before the interviews, study members were sent an advance letter advising them about the survey. The letter was accompanied by detailed information about the survey and the cohort members were free to request further information, or to opt out of the survey at this point. Also, the cohort members could request further information or refuse involvement during all the survey process, including when the interviewer attempted to make an appointment to visit, when the interviewer visited and at any point during the administration of any elements of the surveys. The verbal consent was approved as it was a routine since the beginning of the cohort, in 1970.

\section{Consent for publication}

Not applicable.

\section{Competing interests}

All authors have completed the ICMJE uniform disclosure form at wwW. icmje.org/coi_disclosure.pdf and declare no financial relationships with any organisations that might have an interest in the submitted work in the previous 3 years; no other relationships or activities that could appear to have influenced the submitted work.

\section{Author details}

${ }^{1}$ Centre for Longitudinal Studies (UCL Institute of Education), 55-59 Gordon Square, London WC1H ONU, UK. ²Division of Surgery \& Interventional Science, Faculty of Medical Sciences, University College London, London, UK.

Received: 4 March 2021 Accepted: 11 June 2021

Published online: 28 July 2021

\section{References}

1. Kingston A, Robinson L, Booth $H$, Knapp M, Jagger C, for the MODEM project. Projections of multi-morbidity in the older population in England to 2035: estimates from the population ageing and care simulation (PACSim) model. Age Ageing. 2018;47(3):374-80. https://doi.org/10.1093/ageing/afx2 01

2. Tran J, Norton R, Conrad N, Rahimian F, Canoy D, Nazarzadeh M, et al, Patterns and temporal trends of comorbidity among adult patients with incident cardiovascular disease in the UK between 2000 and 2014: a population-based cohort study. PLoS Med. 2018;15:3. https://doi.org/10.13 71/journal.pmed.1002513.

3. World Health Organization. Multimorbidity: technical series on safer primary care. Geneva: World Health Organization; 2016.

4. Academy of Medical Sciences. Multimorbidity: a priority for global health research. London: Academy of Medical Sciences; 2018.

5. Violan C, Foguet-Boreu Q, Flores-Mateo G, et al. Prevalence, Determinants and Patterns of Multimorbidity in Primary Care: A Systematic Review of Observational Studies. PLoS One. 2014;9:7. https://doi.org/10.1371/journal. pone.0102149.

6. Lehman BJ, David DM, Gruber JA. Rethinking the biopsychosocial model of health: Understanding health as a dynamic system. Soc Personal Psychol. 2017;11:8. https://doi.org/10.1111/spc3.12328.

7. Solis CB, Kelly-Irving M, Fantin R, et al. Adverse childhood experiences and physiological wear- and-tear in midlife: findings from the 1958 British birth cohort. P Natl Acad Sci USA. 2015;112(7):E738-E46. https://doi.org/10.1073/ pnas.1417325112.

8. Ben-Shlomo Y, Cooper R, Kuh D. The last two decades of life course epidemiology, and its relevance for research on ageing. Int J Epidemiol. 2016;45(4):973-88. https://doi.org/10.1093/ije/dyw096.

9. Ben-Shlomo Y, Kuh D. A life course approach to chronic disease epidemiology: conceptual models, empirical challenges and interdisciplinary perspectives. Int J Epidemiol. 2002;31(2):285-93. https://doi.org/10.1093/ ije/31.2.285.

10. Blane $D$, Kelly-Irving M, d'Errico A, et al. Social-biological transitions: how does the social become biological? Longitudinal Life Course Stud. 2013;4(2): 136-46.

11. Gilbert LK, Breiding MJ, Merrick MT, et al. Childhood adversity and adult chronic disease: an update from ten states and the District of Columbia, 2010. Am J Prev Med. 2015;48(3):345-9. https://doi.org/10.1016/j.amepre.2 014.09.006 published Online First: 2014/10/11

12. Anda RF, Butchart A, Felitti VJ, et al. Building a framework for global surveillance of the public health implications of adverse childhood experiences. Am J Prev Med. 2010;39(1):93-8. https://doi.org/10.1016/j.a mepre.2010.03.015 published Online First: 2010/06/16.

13. Humphreys J, Jameson K, Cooper C, Dennison E. Early-life predictors of future multi-morbidity: results from the Hertfordshire cohort. Age Ageing. 2018:47(3):474-8. https://doi.org/10.1093/ageing/afy005.

14. Johnston MC, Black C, Mercer SW, Prescott GJ, Crilly MA. Impact of educational attainment on the association between social class at birth and multimorbidity in middle age in the Aberdeen Children of the 1950s cohort study. BMJ Open. 2019;9:1. https://doi.org/10.1136/bmjopen-2018-024048.

15. Booth HP, Prevost AT, Gulliford MC. Impact of body mass index on prevalence of multimorbidity in primary care: cohort study. Fam Pract. 2014; 31(1):38-43. https://doi.org/10.1093/fampra/cmt061.

16. Lebenbaum M, Zaric GS, Thind A, et al. Trends in obesity and multimorbidity in Canada. Prev Med. 2018;116:173-9. https://doi.org/10.101 6/j.ypmed.2018.08.025 published Online First: 2018/09/09.

17. Park MH, Falconer C, Viner RM, et al. The impact of childhood obesity on morbidity and mortality in adulthood: a systematic review. Obes Rev. 2012; 
13(11):985-1000. https://doi.org/10.1111/j.1467-789X.2012.01015.x published Online First: 2012/06/27.

18. Neeleman J, Sytema S, Wadsworth M. Propensity to psychiatric and somatic ill-health: evidence from a birth cohort. Psychol Med. 2002;32(5):793-803 published Online First: 2002/08/13.

19. Henderson M, Richards M, Stansfeld S, Hotopf M. The association between childhood cognitive ability and adult long-term sickness absence in three British birth cohorts: :a cohort study. BMJ Open. 2012;2:2. https://doi.org/1 0.1136/bmjopen-2011-000777.

20. Brown M, Peters A. 1970 British Cohort Study. Age 46 survey user guide: Institute of Education, 2019.

21. Elliott J, Shepherd P. Cohort profile: 1970 British Birth Cohort (BCS70). Int J Epidemiol. 2006;35(4):836-43. https://doi.org/10.1093/ije/dyl174 published Online First: 2006/08/26.

22. Wadsworth M, Bynner J. A companion to life course studies: the social and historical context of the British birth cohort studies. London: Routledge; 2011. https://doi.org/10.4324/9780203878583.

23. NICE. Multimorbidity: National Institute for Health and Care Excellence, 2017.

24. Gómez A, Conde A, Santana JM, Jorrín A. Diagnostic usefulness of brief versions of alcohol use disorders identification test (AUDIT) for detecting hazardous drinkers in primary care settings. J Stud Alcohol. 2005;66(2):3058. https://doi.org/10.15288/jsa.2005.66.305.

25. Rodgers B, Pickles A, Power C, et al. Validity of the Malaise Inventory in general population samples. Soc Psychiatry Psychiatr Epidemiol. 1999;34(6): 333-41 published Online First: 1999/07/28.

26. Galobardes B, Shaw M, Lawlor DA, et al. Indicators of socioeconomic position (part 2). J Epidemiol Community Health. 2006;60(2):95-101. https:// doi.org/10.1136/jech.2004.028092 published Online First: 2006/01/18.

27. McCartney G, Bartley M, Dundas R, et al. Theorising social class and its application to the study of health inequalities. SSM Popul Health. 2019;7: 015. https://doi.org/10.1016/j.ssmph.2018.10.015 published Online First: 2019/07/13.

28. Elliott C, Murray D, Pearson L. British ability scales. National Foundation for Educational Research: Windsor; 1978.

29. Singh-Manoux A, Ferrie JE, Lynch JW, Marmot M. The role of cognitive ability (intelligence) in explaining the association between socioeconomic position and health: evidence from the Whitehall II prospective cohort study. Am J Epidemiol. 2005;161(9):831-9. https://doi.org/10.1093/aje/kwi1 09.

30. Kuh D, Pierce M, Adams J, et al. Cohort profile: updating the cohort profile for the MRC National Survey of Health and Development: a new clinicbased data collection for ageing research. Int J Epidemiol. 2011;40(1):e1-9. https://doi.org/10.1093/ije/dyq231 published Online First: 2011/02/25.

31. Rutter M, Tizard J, Whitmore K. Education, health and behaviour. London: Longmans; 1970.

32. VanderWeele TJ. Principles of confounder selection. Eur J Epidemiol. 2019; 34(3):211-9. https://doi.org/10.1007/s10654-019-00494-6 published Online First: 2019/03/07.

33. White IR, Royston P, Wood AM. Multiple imputation using chained equations: issues and guidance for practice. Stat Med. 2011;30(4):377-99. https://doi.org/10.1002/sim.4067.

34. Pang M, Kaufman JS, Platt RW. Studying noncollapsibility of the odds ratio with marginal structural and logistic regression models. Stat Methods Med Res. 2016;25(5):1925-37. https://doi.org/10.1177/0962280213505804 published Online First: 2013/10/11.

35. Stirland LE, Gonzalez-Saavedra L, Mullin DS, et al. Measuring multimorbidity beyond counting diseases: systematic review of community and population studies and guide to index choice. BMJ. 2020;368:m160. https://doi.org/1 0.1136/bmj.m160 published Online First: 2020/02/20.

36. Sinnige J, Braspenning J, Schellevis F, et al. The Prevalence of Disease Clusters in Older Adults with Multiple Chronic Diseases - a Systematic Literature Review. PLoS One. 2013;8:11. https://doi.org/10.1371/journal.pone. 0079641.

37. VanderWeele TJ, Mathur MB. Some desirable properties of the Bonferroni correction: is the Bonferroni correction really so bad? Am J Epidemiol. 2019; 188(3):617-8. https://doi.org/10.1093/aje/kwy250

38. VanderWeele TJ, Ding P. Sensitivity Analysis in Observational Research: Introducing the E-Value. Ann Intern Med. 2017;167(4):268. https://doi.org/10. 7326/M16-2607.

39. Barnett K, Mercer SW, Norbury M, Watt G, Wyke S, Guthrie B. Epidemiology of multimorbidity and implications for health care, research, and medical education: a cross-sectional study. Lancet. 2012;380(9836):37-43. https://doi. org/10.1016/S0140-6736(12)60240-2.

40. Li L, Hardy R, Kuh D, Power C. Life-course body mass index trajectories and blood pressure in mid life in two British birth cohorts: stronger associations in the later-born generation. Int J Epidemiol. 2015;44(3):1018-26. https://doi. org/10.1093/ije/dyv106.

41. Lyall DM, Celis-Morales C, Ward J, lliodromiti S, Anderson JJ, Gill JMR, et al. Association of Body Mass Index with Cardiometabolic Disease in the UK biobank a Mendelian randomization study. JAMA Cardiol. 2017;2(8):882-9. https://doi.org/10.1001/jamacardio.2016.5804.

42. Chatterjee S, Khunti K, Davies MJ. Type 2 diabetes. Lancet. 2017;389(10085): 2239-51. https://doi.org/10.1016/S0140-6736(17)30058-2.

43. Bell JA, Hamer M, Batty GD, Singh-Manoux A, Sabia S, Kivimäki M. Incidence of metabolic risk factors among healthy obese adults 20-year follow-up. J Am Coll Cardiol. 2015;66(7):871-3. https://doi.org/10.1016/j.jacc.2015.06.014.

44. Buchanan A, Flouri E, Ten Brinke J. Emotional and behavioural problems in childhood and distress in adult life: risk and protective factors. Aust N Z J Psychiatry. 2002;36(4):521-7. https://doi.org/10.1046/j.1440-1614.2002.01048.x published Online First: 2002/08/10.

45. Henderson M, Hotopf M, Leon DA. Childhood temperament and long-term sickness absence in adult life. Brit J Psychiat. 2009;194(3):220-3. https://doi. org/10.1192/bjp.bp.107.044271.

46. Mensah FK, Hobcraft J. Childhood deprivation, health and development: associations with adult health in the 1958 and 1970 British prospective birth cohort studies. J Epidemiol Commun H. 2008;62(7):599-606. https://doi. org/10.1136/jech.2007.065706.

47. Juster RP, McEwen BS, Lupien SJ. Allostatic load biomarkers of chronic stress and impact on health and cognition. Neurosci Biobehav R. 2010;35(1):2-16. https://doi.org/10.1016/..neubiorev.2009.10.002.

48. Caserta MT, Wyman PA, Wang HY, Moynihan J, O'Connor TG. Associations among depression, perceived self-efficacy, and immune function and health in preadolescent children. Dev Psychopathol. 2011;23(4):1139-47. https:// doi.org/10.1017/S0954579411000526.

49. Stone AL, Becker LG, Huber AM, Catalano RF. Review of risk and protective factors of substance use and problem use in emerging adulthood. Addict Behav. 2012:37(7):747-75. https://doi.org/10.1016/.addbeh.2012.02.014.

50. Dyer ML, Easey KE, Heron J, Hickman M, Munafò MR. Associations of child and adolescent anxiety with later alcohol use and disorders: a systematic review and meta-analysis of prospective cohort studies. Addiction. 2019; 114(6):968-82. https://doi.org/10.1111/add.14575.

51. Goodman A, Joyce R, Smith JP. The long shadow cast by childhood physical and mental problems on adult life. P Natl Acad Sci USA. 2011; 108(15):6032-7. https://doi.org/10.1073/pnas.1016970108.

52. Ning K, Gondek D, Patalay P, Ploubidis GB. The association between early life mental health and alcohol use behaviours in adulthood: a systematic review. PLoS One. 2020;15(2):e0228667. https://doi.org/10.1371/journal.pone. 0228667.

53. Dhalwani NN, O'Donovan G, Zaccardi F, et al. Long terms trends of multimorbidity and association with physical activity in older English population. Int J Behav Nutr Phys Act. 2016;13:8. https://doi.org/10.1186/s12 966-016-0330-9 published Online First: 2016/01/21.

54. Gottfredson LS, Gottfredson LS DIJ, Deary IJ. Intelligence predicts health and longevity, but why? Curr Dir Psychol Sci. 2004;13(1):1-4. https://doi.org/1 0.1111/j.0963-7214.2004.01301001.x

55. Bann D, Johnson W, Li L, Kuh D, Hardy R. Socioeconomic Inequalities in Body Mass Index across Adulthood: Coordinated Analyses of Individual Participant Data from Three British Birth Cohort Studies Initiated in 1946, 1958 and 1970. PLoS Med. 2017;14:1. https://doi.org/10.1371/journal.pmed.1002214.

56. Birnie K, Cooper R, Martin RM, et al. Childhood Socioeconomic Position and Objectively Measured Physical Capability Levels in Adulthood: a Systematic Review and Meta-Analysis. PLoS One. 2011;6:1. https://doi.org/10.1371/ journal.pone.0015564.

57. Galobardes B, Smith GD, Lynch JW. Systematic review of the influence of childhood socioeconomic circumstances on risk for cardiovascular disease in adulthood. Ann Epidemiol. 2006;16(2):91-104. https://doi.org/10.1016/j.a nnepidem.2005.06.053.

58. Hardy R, Kuh D, Langenberg C, et al. Birthweight, childhood social class, and change in adult blood pressure in the 1946 British birth cohort. Lancet. 2003;362(9391):1178-83. https://doi.org/10.1016/50140-6736(03)14539-4.

59. Yang YC, Gerken K, Schorpp K, Boen C, Harris KM. Early-life socioeconomic status and adult physiological functioning: a life course examination of 
biosocial mechanisms. Biodemogr Soc Biol. 2017;63(2):87-103. https://doi. org/10.1080/19485565.2017.1279536.

60. Belbasis L, Savvidou MD, Kanu C, Evangelou E, Tzoulaki I. Birth weight in relation to health and disease in later life: an umbrella review of systematic reviews and meta-analyses. BMC Med. 2016;14(1):147. https://doi.org/10.11 86/s12916-016-0692-5.

61. Wang TG, Huang T, Li YP, Zheng Y, Manson JAE, Hu FB, et al. Low birthweight and risk of type 2 diabetes: a Mendelian randomisation study. Diabetologia. 2016;59(9):1920-7. https://doi.org/10.1007/s00125-016-4019-z.

62. Zanetti D. Birthweight, Type 2 Diabetes Mellitus, and Cardiovascular Disease: Addressing the Barker Hypothesis With Mendelian Randomization (vol 11, e002054, 2018). Circ-Genom Precis Me. 2018;11:9. https://doi.org/10.1161/ HCG.0000000000000051.

63. Myatt L. Placental adaptive responses and fetal programming. J PhysiolLondon. 2006;572(1):25-30. https://doi.org/10.1113/jphysiol.2006.104968.

64. Santos MS, Joles JA. Early determinants of cardiovascular disease. Best Pract Res Cl En. 2012;26(5):581-97. https://doi.org/10.1016/j.beem.2012.03.003.

65. Barker DJ, Winter PD, Osmond C, et al. Weight in infancy and death from ischaemic heart disease. Lancet. 1989;2(8663):577-80. https://doi.org/10.101 6/s0140-6736(89)90710-1 published Online First: 1989/09/09.

66. Collins LM, Schafer JL, Kam CM. A comparison of inclusive and restrictive strategies in modern missing data procedures. Psychol Methods. 2001;6(4): 330-51 published Online First: 2002/01/10.

67. Little R, Rubin DB. Statistical analysis with missing data. Hoboken: Wiley; 2002.

68. Mostafa T, Narayanan M, Pongiglione B, et al. Missing at random assumption made more plausible: evidence from the 1958 British birth cohort. J Clin Epidemiol. 2021;136:44. https://doi.org/10.1016/j.jclinepi.2021. 02.019 .

69. Mujica-Mota RE, Roberts M, Abel G, Elliott M, Lyratzopoulos G, Roland M, et al. Common patterns of morbidity and multi-morbidity and their impact on health-related quality of life: evidence from a national survey. Qual Life Res. 2015;24(4):909-18. https://doi.org/10.1007/s11136-014-0820-7.

70. Vetrano DL, Rizzuto D, Calderon-Larranaga A, et al. Trajectories of functional decline in older adults with neuropsychiatric and cardiovascular multimorbidity: A Swedish cohort study. PLoS Med. 2018;15:3. https://doi. org/10.1371/journal.pmed.1002503.

71. Gallo JJ, Hwang S, Joo JH, Bogner HR, Morales KH, Bruce ML, et al. Multimorbidity, depression, and mortality in primary care: randomized clinical trial of an evidence-based depression care management program on mortality risk. J Gen Intern Med. 2016;31(4):380-6. https://doi.org/10.1 007/s11606-015-3524-y.

\section{Publisher's Note}

Springer Nature remains neutral with regard to jurisdictional claims in published maps and institutional affiliations.

Ready to submit your research? Choose BMC and benefit from:

- fast, convenient online submission

- thorough peer review by experienced researchers in your field

- rapid publication on acceptance

- support for research data, including large and complex data types

- gold Open Access which fosters wider collaboration and increased citations

- maximum visibility for your research: over $100 \mathrm{M}$ website views per year

At BMC, research is always in progress.

Learn more biomedcentral.com/submissions 